\title{
Preliminary Results of Laboratory Tested System for Active Control of Plates VIA LabVIEW and Piezoelectric Elements
}

\author{
R. Trojanowski And J. WiCIAK* \\ Department of Mechanics and Vibroacoustics, AGH - University of Science and Technology \\ al. Mickiewicza 30, 30-059 Kraków, Poland
}

\begin{abstract}
The design and implementation of a labview and PID controller developed for the damping of sinusoidally excited forced vibrations of a plate is presented. The plate used in the study is clamped at one side and free at the others aluminum plate with five piezo elements attached. Two of them act as sensors, and three as actuators (one for vibration source, and two for active vibration control). Selected experimental results are used to demonstrate the effectiveness of the proposed platform.
\end{abstract}

PACS numbers:

\section{Introduction}

In most machines vibration is an unwanted side effect generated during their work. It reduces quality of products, damages the machine and sometimes afflicts health of machine operator [1]. For most of the XX century only passive systems could be used for vibration reduction. But that has changed in last decades. Thanks to IT development we have microprocessors that allow us to use real-time calculations. New materials introduced (PZT, PVDF, elastomagnetic composites) that can act as sensors or actuators both small and effective. This opened the doors to active methods. In 1991 E. Dimitradis, C. Fuller, C. Rogers presented the theory for excitation of two-dimensional thin elastic structures by piezoelectric actuators, followed by experimental excitation of a rectangular plate [2]. In 1995 J.L. van Niekerk et al. introduced control system using $\mathrm{H}_{2}$ optimal control procedure [3]. Today active methods can be divided to: active noise control (ANC), active vibration control (AVC), active noise-vibration control (ANVC), active structural acoustic control (ASAC) $[4,5]$. In most cases the problem does not lie in sensors or actuators, but their placement on the structure [6-10] and the control system optimization. The following problems arise. Should we use feedback loop, or perhaps feedforward loop [4]? Is it better to have multi input multi output (MIMO), or perhaps single input single output (SISO) [4]? These are the things we should consider today.

\section{Description}

In this article the problem of active vibration control of a plate using piezoelectric elements and LabVIEW envi-

\footnotetext{
* corresponding author; e-mail: wiciak@uci.agh.edu.pl
}

ronment is presented. For this laboratory stand (Figs. 1 and 2) consisting of an aluminum plate with piezo elements attached, amplifiers, personal computer with LabVIEW software and DAQ board is created. Our object of interest is one side clamped aluminum plate with five piezoelectric elements attached. Two of them are used as sensors, and three as actuators (one of them as vibration source, and the other two for active vibration control). Figure 1 shows our laboratory stand.

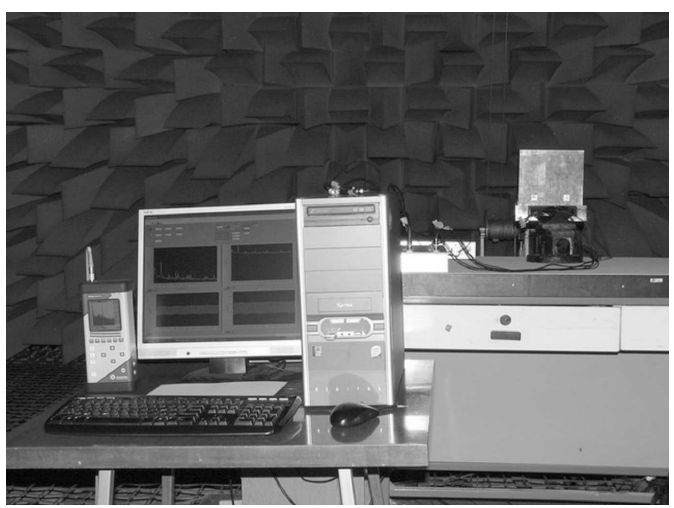

Fig. 1. Laboratory stand.

A sinusoidal signal of given plate resonance frequency is used as a vibration source. The frequency range use in research is supposed to be $1-3000 \mathrm{~Hz}$. Due to the high low frequencies damping that is presented from mounting first notable excitation is at about $110 \mathrm{~Hz}$. Therefore the frequency range is changed to $100-3000 \mathrm{~Hz}$. This translates to 12 resonance frequencies.

Locations of piezo elements as well as plate dimensions are shown in Fig. 3. The locations is determined from literature [4]. 


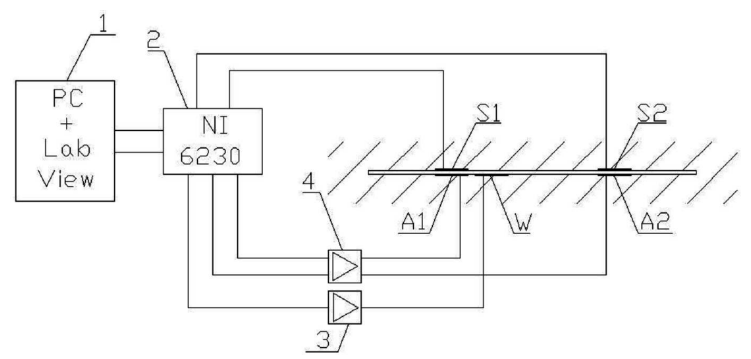

Fig. 2. Laboratory stand, schematics.

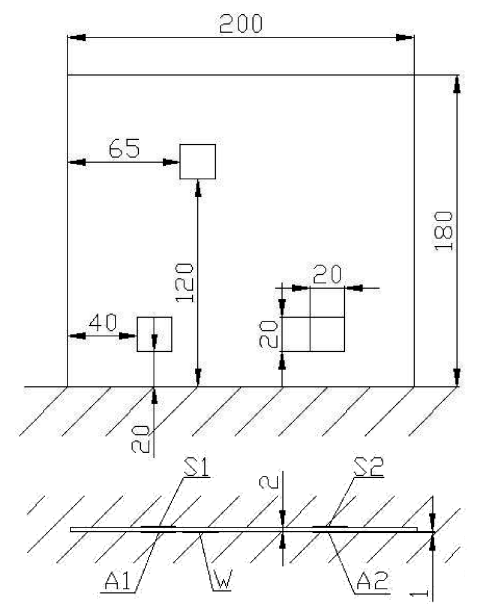

Fig. 3. Plate dimensions and piezo elements layout.

The study is divided in two parts. The first one is active vibration control using only one actuator. In this stage few program configurations are tested, to choose the most suitable one. After the initial study the program is expanded with the second PID regulator [11]. That approach would allow different parameters on every channel (if necessary). After the second part, the system is tried out with random signal (Gaussian noise). Unfortunately during the tests the system proved unstable for random signals. After consulting this with NI staff it is been assumed that with current frequency range and standard operating system (like Windows or Linux) it will not work. Two possible solutions would be either bringing frequency below $100 \mathrm{~Hz}$, or changing OS to real-time. For now the most that system could deal with are multi-tonal signals (but that needs verification).

The VI front panel, which allows us to control vibration source parameters, PID parameters (proportional gain $K$, integral time $T_{i}$, derivative time $T_{d}$, output range and setpoint) is shown in Fig. 4. It is also used for results presentation in form of FFT graphs, time signals from sensors (this allows us to spot errors and anomalies), and numerical values of amplitudes for easier readings.

Figure 5 shows simplified block diagram. It is not $100 \%$ accurate, but shows general view, and is not difficult to read.

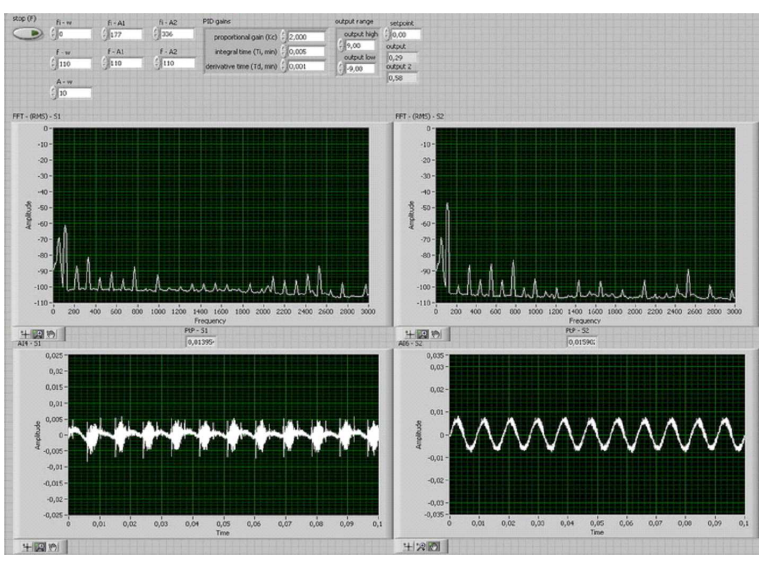

Fig. 4. VI front panel.

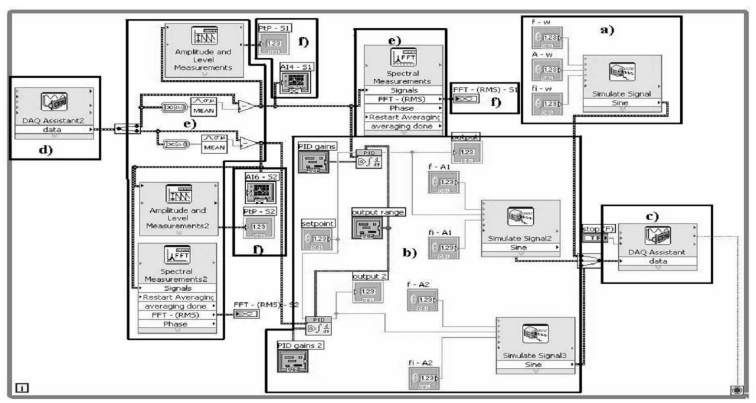

Fig. 5. Simplified block diagram: (a) vibration source, (b) control (PID gain), (c) data sending, (d) data acquisition, (e) data analysis, (f) results presentation.

\section{Results}

Chosen experimental results expressed as displacement amplitude are presented in Figs. 6-8.

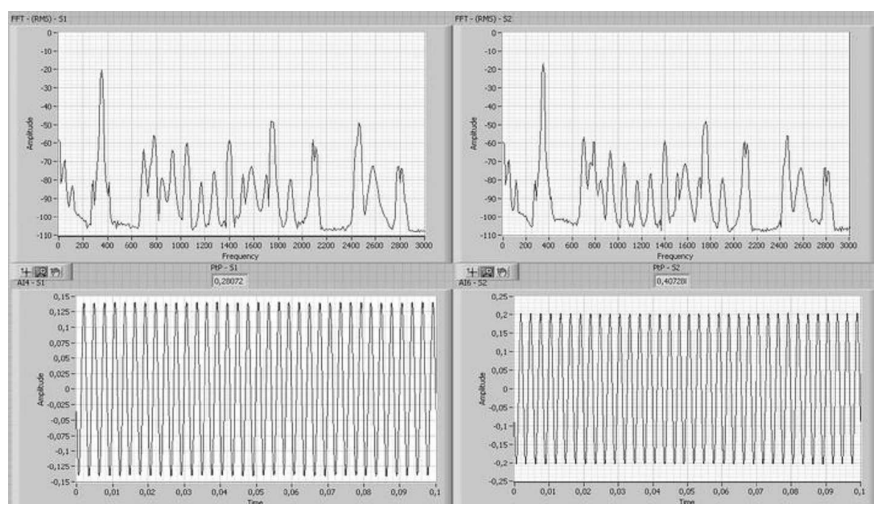

Fig. 6. Results for $350 \mathrm{~Hz}$ without damping.

Figure 6 shows the results for undamped vibrations of $350 \mathrm{~Hz}$. Differences between channels are probably the effect of position of piezo element responsible for vibration source, and attachment of piezo elements (it was done manually). 


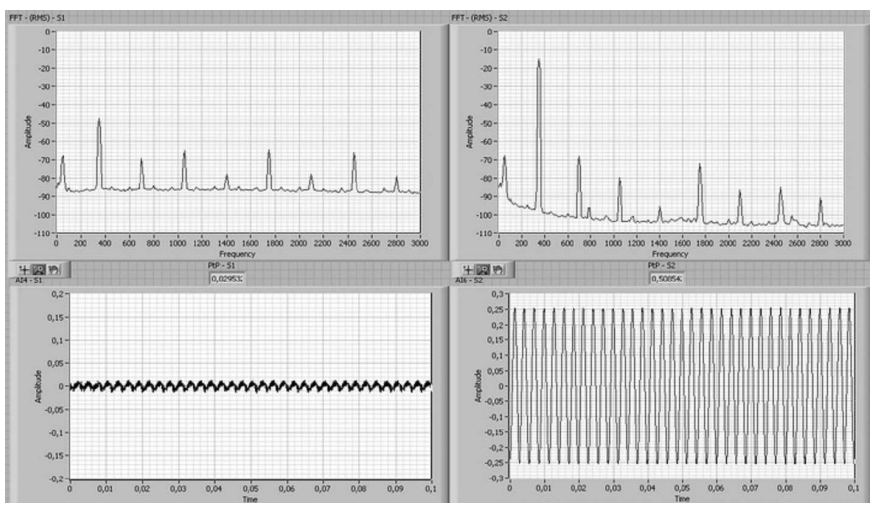

Fig. 7. Results for $350 \mathrm{~Hz}$ with 1 channel damping.

Our goal is to minimize vibration amplitude, therefore the control cost function is taken as:

$$
J=\min \sum_{i=1}^{\mathrm{N}} \stackrel{2}{x_{i}} \mid
$$

where $x_{i}$ is the sensor voltage signal, $N$ - is the number of independent sensors used.

For the case with one actuator running, the approach gives us good reduction on sensor 1 (average of $23.1 \mathrm{~dB}$, Fig. 9), but as Fig. 10 indicates it's only local. On sensor 2 we have average of $-0.3 \mathrm{~dB}$.

For the case with two actuators running, we have an average reduction of $18.9 \mathrm{~dB}$ on sensor 1 , and $20.3 \mathrm{~dB}$ on sensor 2. Of course for some frequencies the results were worse than while using 1 channel, but it's probably a problem with control system optimization.

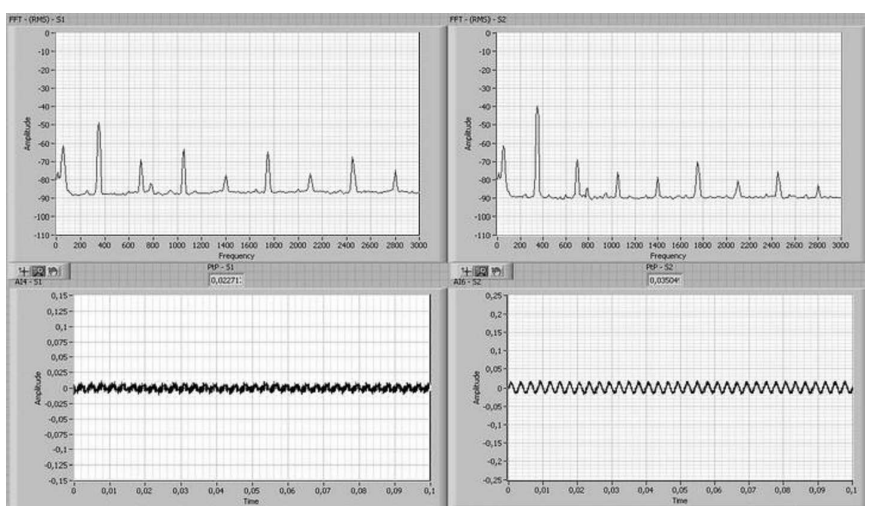

Fig. 8. Results for $350 \mathrm{~Hz}$ with 2 channels damping.

Table shows some of the results. Columns represent: the case $(1-$ no damping, $2-1$ channel damping, 3 - 2 channels damping), $f[\mathrm{~Hz}]$ - vibration source frequency, $A_{\mathrm{WRMS}}$ - vibration source voltage, $\mathrm{K}_{1}, \mathrm{~K}_{2}-$ proportional gains for PID's, $T_{i 1}, T_{i 2}-$, integral times for PID's, $T_{d 1}, T_{d 2}$ - derivative times for PID's, $A_{\mathrm{A} 1 \mathrm{RMS}}$, $A_{\mathrm{A} 2 \mathrm{RMS}}$ - voltages applied to actuators, $\phi_{1}, \phi_{2}$ - actuators signals phases, $A_{\mathrm{S} 1 \mathrm{RMS}}, A_{\mathrm{S} 2 \mathrm{RMS}}$ - voltage levels from sensors. The reference level for $A_{\mathrm{SRMS}}$ is $10^{-6}$.
It can be seen that for the first two frequencies the applied voltage is significantly higher than for the rest of them. That is because of the before mentioned damping. Even after the increase of voltage it can be seen that the response is still weaker.

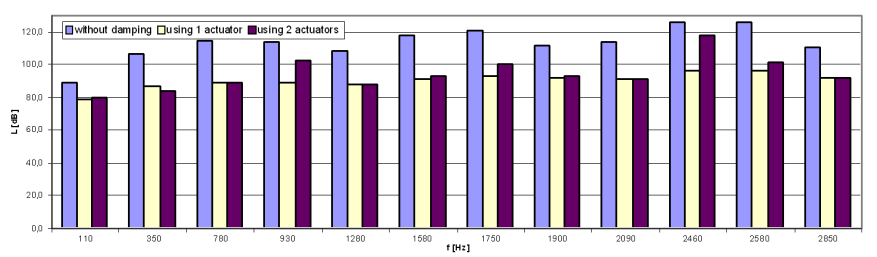

Fig. 9. Results for channel 1.

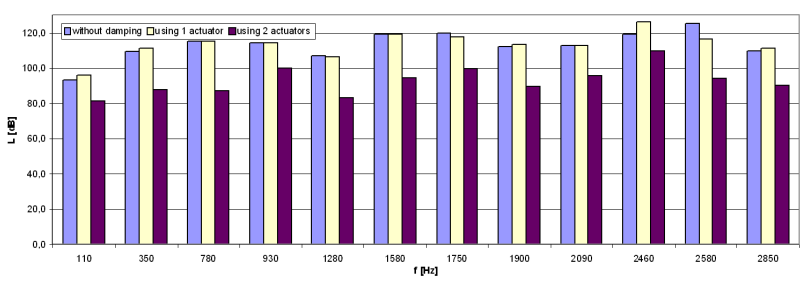

Fig. 10. Results for channel 2.

\section{Conclusions}

This work presents results of preliminary studies of active vibration control with the use of LabVIEW software. Tests were carried out for 1 and 2 piezoelectric actuators. Using 1 actuator local vibration reduction was observed (sensor 1), with (in most cases) no significant changes on second sensor. With 2 actuators significant reduction can be seen on both sensors. This way two local zones of reduction were obtained. Still there is shortage of information about global image of plate vibration. Therefore for future studies optical systems were considered for plate global vibration levels measurements.

At this stage presented system is capable of reducing plate vibration, considering that we are dealing with sinusoidal vibrations, not random signals. After some minor changes in the structure signals consisting of several sinuses could also be reduced. There are also problems with time that reduction takes.

After analyses and discussions with Nationals Instruments staff it was concluded, that there are two ways to deal with random signals. One way would be to limit frequency range to $100 \mathrm{~Hz}$ (quite difficult considering, that first significant response to excitation is observed at $110 \mathrm{~Hz}$ ). The other would be to change computer Operating System (OS) from Windows to some Real Time system. 
Results

TABLE

\begin{tabular}{|c|c|c|c|c|c|c|c|c|c|c|c|c|c|c|}
\hline Case & $\begin{array}{c}\mathrm{f} \\
{[\mathrm{Hz}]}\end{array}$ & $\begin{array}{c}A_{\mathrm{WRMS}} \\
{[\mathrm{V}]}\end{array}$ & $K_{1}$ & $\begin{array}{c}\mathrm{Ti}_{1} \\
{[\mathrm{~min}]}\end{array}$ & $\begin{array}{c}\mathrm{Td}_{1} \\
{[\mathrm{~min}]}\end{array}$ & $K_{2}$ & $\begin{array}{c}\mathrm{Ti}_{2} \\
{[\mathrm{~min}]}\end{array}$ & $\begin{array}{c}\mathrm{Td}_{2} \\
{[\mathrm{~min}]}\end{array}$ & $\begin{array}{c}A_{\mathrm{A} 1 \mathrm{RMS}} \\
{[\mathrm{V}]}\end{array}$ & $\begin{array}{c}\phi_{1} \\
{\left[{ }^{\circ} \mathrm{C}\right]}\end{array}$ & $\begin{array}{c}A_{\mathrm{A} 2 \mathrm{RMS}} \\
{[\mathrm{V}]}\end{array}$ & $\begin{array}{c}\phi_{2} \\
{\left[{ }^{\circ} \mathrm{C}\right]}\end{array}$ & $\begin{array}{c}A_{\mathrm{S} 1 \mathrm{RMS}} \\
\text { [dB] }\end{array}$ & $\begin{array}{c}A_{\mathrm{S} 2 \mathrm{RMS}} \\
{[\mathrm{dB}]}\end{array}$ \\
\hline 1 & 110 & 127 & 0 & 0 & 0 & 0 & 0 & 0 & 0.00 & 0 & 0.00 & 0 & 89.5 & 93.0 \\
\hline 2 & 110 & 127 & 2 & 0.01 & 0 & 0 & 0 & 0 & 2.12 & 233 & 0.00 & 0 & 78.6 & 96.3 \\
\hline 3 & 110 & 127 & 2 & 0.005 & 0.001 & 2 & 0.005 & 0.001 & 2.05 & 177 & 4.10 & 336 & 79.9 & 81.1 \\
\hline 1 & 350 & 127 & 0 & 0 & 0 & 0 & 0 & 0 & 0.00 & 0 & 0.00 & 0 & 106.0 & 109.2 \\
\hline 2 & 350 & 127 & 2 & 0.01 & 0 & 0 & 0 & 0 & 9.26 & 190 & 0.00 & 0 & 86.5 & 111.1 \\
\hline 3 & 350 & 127 & 2 & 0.005 & 0.001 & 2 & 0.005 & 0.001 & 8.20 & 206 & 14.00 & 202 & 84.2 & 87.9 \\
\hline 1 & 780 & 38 & 0 & 0 & 0 & 0 & 0 & 0 & 0.00 & 0 & 0.00 & 0 & 114.5 & 115.5 \\
\hline 2 & 780 & 38 & 2 & 0.01 & 0 & 0 & 0 & 0 & 11.17 & 335 & 0.00 & 0 & 89.0 & 115.4 \\
\hline 3 & 780 & 38 & 3 & 0.005 & 0 & 3 & 0.005 & 0 & 11.17 & 335 & 16.33 & 113 & 88.8 & 87.4 \\
\hline 1 & 930 & 38 & 0 & 0 & 0 & 0 & 0 & 0 & 0.00 & 0 & 0.00 & 0 & 114.1 & 114.4 \\
\hline 2 & 930 & 38 & 2 & 0.01 & 0 & 0 & 0 & 0 & 12.02 & 121 & 0.00 & 0 & 89.0 & 114.4 \\
\hline 3 & 930 & 38 & 3 & 0.005 & 0 & 3 & 0.005 & 0 & 14.99 & 123 & 11.95 & 314 & 102.0 & 100.1 \\
\hline 1 & 1280 & 38 & 0 & 0 & 0 & 0 & 0 & 0 & 0.00 & 0 & 0.00 & 0 & 108.1 & 106.9 \\
\hline 2 & 1280 & 38 & 2 & 0.01 & 0 & 0 & 0 & 0 & 6.22 & 65 & 0.00 & 0 & 87.6 & 106.4 \\
\hline 3 & 1280 & 38 & 3 & 0.005 & 0 & 3 & 0.005 & 0 & 6.15 & 58 & 5.80 & 58 & 88.4 & 83.4 \\
\hline 1 & 1580 & 38 & 0 & 0 & 0 & 0 & 0 & 0 & 0.00 & 0 & 0.00 & 0 & 118.0 & 119.4 \\
\hline 2 & 1580 & 38 & 2 & 0.01 & 0 & 0 & 0 & 0 & 14.71 & 308 & 0.00 & 0 & 91.3 & 119.4 \\
\hline 3 & 1580 & 38 & 3 & 0.005 & 0 & 3 & 0.005 & 0 & 10.18 & 336 & 12.59 & 334 & 93.2 & 94.5 \\
\hline 1 & 1750 & 38 & 0 & 0 & 0 & 0 & 0 & 0 & 0.00 & 0 & 0.00 & 0 & 120.6 & 119.7 \\
\hline 2 & 1750 & 38 & 2 & 0.01 & 0 & 0 & 0 & 0 & 30.26 & 179 & 0.00 & 0 & 93.1 & 117.9 \\
\hline 3 & 1750 & 38 & 3 & 0.005 & 0 & 3 & 0.005 & 0 & 28.64 & 193 & 18.60 & 6 & 100.3 & 99.7 \\
\hline 1 & 1900 & 38 & 0 & 0 & 0 & 0 & 0 & 0 & 0.00 & 0 & 0.00 & 0 & 111.5 & 112.3 \\
\hline 2 & 1900 & 38 & 2 & 0.01 & 0 & 0 & 0 & 0 & 8.49 & 116 & 0.00 & 0 & 91.6 & 113.5 \\
\hline 3 & 1900 & 38 & 3 & 0.005 & 0 & 3 & 0.005 & 0 & 4.74 & 114 & 11.53 & 156 & 93.1 & 89.9 \\
\hline 1 & 2090 & 38 & 0 & 0 & 0 & 0 & 0 & 0 & 0.00 & 0 & 0.00 & 0 & 113.6 & 113.1 \\
\hline 2 & 2090 & 38 & 2 & 0.01 & 0 & 0 & 0 & 0 & 11.95 & 287 & 0.00 & 0 & 91.5 & 112.6 \\
\hline 3 & 2090 & 38 & 3 & 0.005 & 0 & 3 & 0.005 & 0 & 12.23 & 287 & 11.74 & 265 & 91.1 & 95.7 \\
\hline
\end{tabular}

\section{Acknowledgments}

This study is a part of the research project N N504 078038 supported by the Ministry of Science and Higher Education, Poland.

\section{References}

[1] M.S. Kozień, J. Wiciak, Archives of Acoustics 33, 4, 643 (2008).

[2] E. Dimitradis, C. Fuller, C. Rogers, J. of Vibration and Acoustics 113, 100 (1991).

[3] L. van Niekerk, B.H. Tongue, A.K. Packard, J. of Sound and Vibration 183, 643 (1995).

[4] P. Gardonio, Sensor-Actuator Transducers for Smart Panels, ACTIVE 2006, Australia 2006.
[5] C.H. Hansen, S.D. Snyder, Active control of noise and vibration, E\& FN Spon, 1997.

[6] A. Brański, S. Szela, Archives of Control Sciences 17, 4, 357 (2007).

[7] A. Brański, S. Szela, Archives of Acoustics 33, 4, 521 (2008).

[8] P. Gardonio, S.J. Elliott, J. Acoust. Soc. Am. 117, 2046 (2005).

[9] M.S. Kozień, J. Wiciak, Acta Phys. Pol. A 116, 348.

[10] J. Wiciak, The European Physical Journal. Special Topics 154, 229 (2008).

[11] K. Pietrusiewicz, Control Engineering Poland 5, 20 (2007).

[12] C.R. Fuller, S.J. Elliott, P.A. Nelson, Active Control of Vibration, Academic Press ISBN 1996. 